\title{
Imaging of Pancreatic Carcinoma on Multidetector Computed Tomography, A Tertiary Care Experience at Liaquat National Hospital, Karachi
}

\author{
Rizwan Ajmal ${ }^{1}$, Saleha Anwar ${ }^{*}$, Muhammad Ayub Mansoor ${ }^{1}$, Asif Mateen ${ }^{1}$, Sadaf Nasir ${ }^{1}$ and Bushra Rehan ${ }^{1}$ \\ 'Department of Radiology, Liaquat National Hospital and Medical College, Karachi, Pakistan
}

\begin{abstract}
Introduction: Pancreatic cancer is a lethal disease. The mortality rate for pancreatic tumor has changed over the last 20 years. Early diagnosis of pancreatic carcinoma is very important for therapeutic decisions and surgical planning. Contrast enhance CT facilitated the detection of primary tumor and staging.

Objective: This study is to evaluate various presentations of pancreatic carcinomas on their initial MDCT (Multidetector Computed Tomography) and to evaluate its resectability and to compare CT features among resectable and non-resectable tumors.

Methodology: All the patients underwent multi-phasic CT scan on a 16-slice MDCT. CT findings were analyzed included tumor location, size, enhancement pattern, nodal disease, duct dilatations, vascular involvement and evidence of metastatic disease.

Results: Total 63 records of patients examined during 2017 and 2019 meeting the inclusion criteria were reviewed. The average age at time of MDCT examination was $62.51 \pm 13.17$ years. The disease was more common in males $(n=36,57.1 \%)$. Out of 63 pancreatic tumors, $14(22.22 \%)$ tumors were identified as resectable tumors on MDCT examination. Tumor size ( $p<0.001)$, peripancreatic nodes $(p=0.006)$, contrast enhancement $(p=0.018)$, vessel involvement $(p<0.001)$, ascites $(p=0.006)$, hepatic metastases $(p=0.001)$ and peripheral organ involvement $(p<0.001)$ were significantly different among resectable and non-resectable tumors.
\end{abstract}

Conclusion: MDCT is an excellent and most commonly used modality for diagnosis and staging of pancreatic carcinoma particularly with a high sensitivity for detection of vascular invasion and metastatic disease.

Keywords: Pancreatic carcinoma, MDCT abdomen, resectable, non-resectable.

\section{INTRODUCTION}

Pancreatic carcinoma is a worldwide health problem and it is the second most common gastrodigestive tumor after colorectal carcinoma [1-5]. At the moment of diagnosis $40 \%$ to $50 \%$ of cases have already metastasized and around 40 percent patients suffer locally advanced unresectable disease [6]. The overall survival rate is poor [7-10]. The five-year survival including all stages of pancreatic carcinoma is around $5 \%$ to $6 \%[11,12]$. The causes of pancreatic cancer are not known sufficiently; however, multiple risk factors have been identified such as smoking, obesity, life style, diabetes, alcohol, dietary factors and chronic pancreatitis [13-16]. These risk factors are divided into two broad categories: modifiable and non-modifiable risk factors [17]. There are no current screening recommendations for the pancreatic cancer, so the primary prevention is of utmost importance [18]. Surgical resection is the only treatment for majority of patients and pre-operative evaluation of masses is essential [7]. Pre-operative CT evaluation included tumor location, size, enhancement pattern, nodal disease, duct dilatations, vascular involvement and evidence of metastatic disease [19]. The first successful two-stage pancreaticoduodenectomy is credited to German surgeon

*Corresponding Author: Saleha Shahzad, Department of Radiology, Liaquat National Hospital and Medical College, Karachi, Pakistan;

Email:drsalehashahzad@gmail.com

Received: June 16, 2020; Revised: July 03, 2020; Accepted: July 13, 2020

DOI: https://doi.org/10.37184/lntbj.2708-7808.2.4
Walter Carl Eduard [20]. There are two main tumor types of pancreatic cancer, the adenocarcinoma accounts for $85 \%$ of cases and pancreatic endocrine tumors accounts for $5 \%$ cases [21-23]. The peri-ampulary neoplasms are the deadliest cancers [7]. Patients having pancreatic carcinoma rarely exhibit symptoms in the early stages of disease, so the disease quite advances when it is diagnosed [24]. Imaging of pancreas is very challenging because of its difficult anatomical location in the retro peritoneum and its relationship with the retroperitoneal vessels and adjacent bowel [19, 25, 26]. Improvement in CT technology during past few decades have increased the detection accuracy and tumor characterization and now multiphasic multiplanar imaging is mandatory for pancreatic imaging [27]. MDCT is the most convenient, efficient, non-invasive technique for excellent visualization of pancreatic cancer regarding contrast enhancement, evaluation of peri-pancreatic structures and metastatic diseases [28-32]. The 3D multiplanar reformatted images are used to solve the diagnostic problems [33]. Since the pancreatic carcinomas have a very high capacity to metastasize at an earlier stage, the time between the diagnostic/ staging CT needs to be shortest and some studies recommend that this time should not be over 25 days [13]. Our study is to evaluate various presentations of pancreatic carcinomas on their initial MDCT and to evaluate its resectability and to compare CT features among resectable and nonresectable tumors. 


\section{MATERIALS AND METHODS}

This retrospective study included 63 admitted and out patients with clinical findings of pancreatic mass referred to the CT Department of Liaquat National Hospital during 3 year period from Jan 2017 to Aug 2019. Research assistants abstracted data from patient's medical records and imaging reports. No personal information such as address, contact no was recorded to ensure patient confidentiality. Patients having renal impairment or previous contrast allergy were already excluded from the study. The tumor was defined as resectable when there is no extra pancreatic tumor including absence of peritoneal and hepatic metastases, patency of the superior mesenteric-portal vein confluence, and the presence of a tissue plane between the tumor and the local arterial structures, including the celiac axis, common hepatic artery, and superior mesenteric artery.

\section{MDCT TECHNIQUE}

If is very important to conduct high quality CT imaging to confirm the presence of tumor and access the spread of disease. Since the pancreatic tumors have a high tendency to metastasize at an early stage the time between the diagnostic CT and surgery needs to be the shortest possible. The study was performed using a 16-slice MDCT. Procedure preparation includes low residual diet one day before the procedure and fasting of about 4 to 6 hours prior to contrast CT examination. Patient reassurance and brief explanation of procedure were given to all the patients. All the patients were examined in supine position and patients were instructed to remain stable during examination along with suspended breathing during scanning. Opacification of gastrointestinal tract was done with diluted $20 \mathrm{ml}$ of nonionic contrast material in $1000 \mathrm{ml}$ of water. The oral contrast was given in three divided doses before the examination. Pre contrast scanning of whole abdomen was performed in all patients from the level of diaphragm. After the pre contrast $\mathrm{CT}$ the post contrast scan was done after automatic injection of nonionic contrast media $(300 \mathrm{mg}$ iodine $/ \mathrm{ml})$ at a rate of $5 \mathrm{ml} / \mathrm{sec}$. The volume of contrast media was calculated according to patient's weight. The arterial phase starts 20 to 35 seconds after start of injection, the portovenous phase and the delayed phase begin at 70 and 180 seconds after initiation of IV contrast respectively. If the CT of chest is also required it can be included in the porto venous phase of study by performing thoraco-abdominal scanning. Image data was reconstructed with $1 \mathrm{~mm}$ slice thickness and transferred to work station for image analysis. The arterial phase is very helpful in detecting hyper vascular tumors and the portovenous phase was important for detection of hypo vascular tumors and for metastatic disease.

\section{STRUCTURED REPORTING}

As imaging plays a vital role in pancreatic carcinoma imaging, an accurate and concise report is needed so that all pertinent findings are conveyed to the referring clinicians. Structured reports are efficient and more accurate for referring clinicians as compared to the free style reports and structured reports are more preferred by the clinicians [34-37]. Structured reporting provides superior evaluation of pancreatic cancer, facilitates surgical planning's and also increases the surgeon's confidence about tumors' resectability [38].

\section{DATA ANALYSIS PLAN}

Statistical Package IBM SPSS (version 20) was used to process and analyze the collected data. Frequencies and percentages were computed for qualitative variables. Continuous variable 'age' was presented as mean \pm standard deviation. Pearson chi-square/ Fisher-exact test was applied as appropriate to assess association of tumor resectability with patients' clinical and demographic variables. Statistical significance was defined based on a two-tailed $p$-value $<0.05$.

\section{RESULTS}

Total 63 records were reviewed in accordance with the inclusion criteria. The average age of study participants was $62.51 \pm 13.17$ years. Most of the patients presented with the disease were males ( $n=36,57.1 \%)$. In MDCT examination, the majority of the patients had tumor size in range of $2-5 \mathrm{~cm}(n=32,50.8 \%)$ followed by $>5 \mathrm{~cm}(\mathrm{n}=18,28.6 \%)$ and within $2 \mathrm{~cm}(\mathrm{n}=13,20.6 \%)$. Almost half of the tumors were in region of pancreatic head $(n=28,44.4 \%)$ while $13(20.6 \%)$ and $9(14.3 \%)$ tumors were located in the body and tail respectively. 13 $(20.63 \%)$ tumors were located in more than one region. $7(11.1 \%)$ were located in both head and body. $6(9.5 \%)$ were in region of body and tail. Intrahepatic biliary dilatation was seen in 37 patients $(58.7 \%)$ while visceral involvement and pancreatic duct dilatation were seen in 43 patients $(68.3 \%)$, and $42(66.7 \%)$ respectively. Contrast enhancement was homogenous in 32 patients $(50.8 \%)$ and heterogeneous in 31 patients $(49.2 \%)$. Ascites, hepatic metastasis and peripheral involvement were found ( $n=21,38.3 \%),(n=2438.5 \%),(n=2946.0 \%)$. Plural effusion and pulmonary metastasis were seen in 9 patients $(14.3 \%)$. Pancreatic calcifications and colangitic abscesses were only seen in less than 5 individuals $(n=4,6.3 \%)(n=1,1.6 \%)$. Based on the MDCT findings, out of 63, $14(22.22 \%)$ tumors were resectable (Fig. 1).

Tumor size was significantly different among resectable and non-resectable tumors $(p<0.001)$. Among 13 $(20.63 \%)$ patients with tumors size <2cm, 9 (69.2\%) tumors were resectable which was significantly higher resectability rate as compared to patients who presented with tumor size $2-5 \mathrm{~cm}$ while none of the tumor was resectable among patients with tumor size $>5 \mathrm{~cm}$. Frequency of peripancreatic nodes was also significantly different among resectable and non-resectable tumors $(p=0.006)$. Out of total $10(15.87 \%)$ patients without the involvement of peripancreatic nodes, resectable tumors were $6(60 \%)$ which was significantly higher as compared to those with involvement of peripancreatic 
nodes $(n=8,15.1 \%)$. Finding of resectable tumor on MDCT was also significantly associated with contrast enhancement $(p=0.018)$. The proportion of resectable tumors was high for homogenous enhancement disease $(n=11,34.4 \%)$ than the proportion of resectable tumors for heterogeneous enhancement disease $(n=3,9.7 \%)$. None of the tumors was resectable in case of vessel involvement $(p<0.001)$, ascites $(p=0.006)$, hepatic metastasis $(p=0.001)$ and peripheral organ involvement $(p<0.001)$ (Table 1).

Table 1: Patients' demographic and clinical characteristics and their comparison among resectable and non-resectable tumors.

\begin{tabular}{|c|c|c|c|c|}
\hline- & $\begin{array}{c}\text { Resectable Tumors } \\
\mathrm{n}(\%)\end{array}$ & $\begin{array}{c}\text { Non-resectable Tumors } \\
\mathrm{n}(\%)\end{array}$ & $\begin{array}{l}\text { Total } \\
\text { n (\%) }\end{array}$ & $p$-value \\
\hline Age (in years) \# & $61.50(59.50-69)$ & $62(55-73)$ & $62(55-71)$ & 0.888 \\
\hline \multicolumn{5}{|l|}{ Gender } \\
\hline Female & $6(22.2)$ & $21(77.8)$ & $27(100)$ & \multirow{2}{*}{1.00} \\
\hline Male & $8(22.2)$ & $28(77.8)$ & $36(100)$ & \\
\hline \multicolumn{5}{|l|}{ No. of Tumor Site Involved } \\
\hline Single site was involved & $14(28)$ & $36(72)$ & $50(100)$ & \multirow{2}{*}{0.055} \\
\hline Two sites were involved & $0(0)$ & $13(100)$ & $13(100)$ & \\
\hline \multicolumn{5}{|l|}{ Tumor Size } \\
\hline$<2 \mathrm{~cm}$ & $9(69.2)$ & $4(30.8)$ & $13(100)$ & \multirow{3}{*}{$t^{* *}<0.001$} \\
\hline $2-5 \mathrm{~cm}$ & $5(15.6)$ & $27(84.4)$ & $32(100)$ & \\
\hline$>5 \mathrm{~cm}$ & $0(0)$ & $18(100)$ & $18(100)$ & \\
\hline \multicolumn{5}{|l|}{ Peripancreatic Nodes } \\
\hline No & $6(60)$ & $4(40)$ & $10(100)$ & \multirow{2}{*}{$t^{\star *} 0.006$} \\
\hline Yes & $8(15.1)$ & $45(84.9)$ & $53(100)$ & \\
\hline \multicolumn{5}{|l|}{ Contrast Enhancement } \\
\hline Homogenous enhancement & $11(34.4)$ & $21(65.6)$ & $32(100)$ & \multirow{2}{*}{ *0.018 } \\
\hline Heterogeneous enhancement & $3(9.7)$ & $28(90.3)$ & $31(100)$ & \\
\hline \multicolumn{5}{|l|}{ Pancreatic Calcifications } \\
\hline Yes & $1(25)$ & $3(75)$ & $4(100)$ & \multirow{2}{*}{$\$ 1.00$} \\
\hline No & $13(22)$ & $46(78)$ & $459(100)$ & \\
\hline \multicolumn{5}{|l|}{ IBDs and CBD Dilatation } \\
\hline No & $4(15.4)$ & $22(84.6)$ & $26(100)$ & \multirow{2}{*}{0.274} \\
\hline Yes & $10(27)$ & $27(73)$ & $37(100)$ & \\
\hline \multicolumn{5}{|l|}{ Vessel Involvement } \\
\hline No & $14(70)$ & $6(30)$ & $20(100)$ & \multirow{2}{*}{$t^{* *}<0.001$} \\
\hline Yes & $0(0)$ & $43(100)$ & $43(100)$ & \\
\hline \multicolumn{5}{|l|}{ PD Dilatation } \\
\hline No & $6(28.6)$ & $15(71.4)$ & $21(100)$ & \multirow{2}{*}{0.522} \\
\hline Yes & $8(19)$ & $34(81)$ & $42(100)$ & \\
\hline \multicolumn{5}{|l|}{ Ascites } \\
\hline No & $14(31.1)$ & $31(68.9)$ & $45(100)$ & \multirow{2}{*}{$t^{\star *} 0.006$} \\
\hline Yes & $0(0)$ & $18(100)$ & $18(100)$ & \\
\hline \multicolumn{5}{|l|}{ Pleural Effusion } \\
\hline No & $14(25.9)$ & $40(74.1)$ & $54(100)$ & \multirow{2}{*}{ †0.188 } \\
\hline Yes & $0(0)$ & $9(100)$ & $9(100)$ & \\
\hline \multicolumn{5}{|l|}{ Pulmonary Metastases } \\
\hline No & $14(25.9)$ & $40(74.1)$ & $54(100)$ & \\
\hline Yes & $0(0)$ & $9(100)$ & $9(100)$ & 0.188 \\
\hline Hepatic Metastases & & & & \\
\hline No & $14(35.9)$ & $25(64.1)$ & $39(100)$ & $* * 0001$ \\
\hline Yes & $0(0)$ & $24(100)$ & $24(100)$ & 0.001 \\
\hline Cholangitic Abscesses & & & & \\
\hline No & $14(22.6)$ & $48(77.4)$ & $62(100)$ & \\
\hline Yes & $0(0)$ & $1(100)$ & $1(100)$ & +1.00 \\
\hline Peripheral Organ Involvemer & & & & \\
\hline No & $14(41.2)$ & $20(58.8)$ & $34(100)$ & $* *<0001$ \\
\hline Yes & $0(0)$ & $29(100)$ & $29(100)$ & $x^{n}<0.001$ \\
\hline
\end{tabular}

\#: Age was non-normally distributed between two groups and expressed as median (interquartile range). Mann-Whitney $U$ test was applied to compare age between two groups.

t: Fisher-exact test is reported, *denotes statistical significance at $p<0.05,{ }^{* *}$ denotes statistical significance at $p<0.01$. 


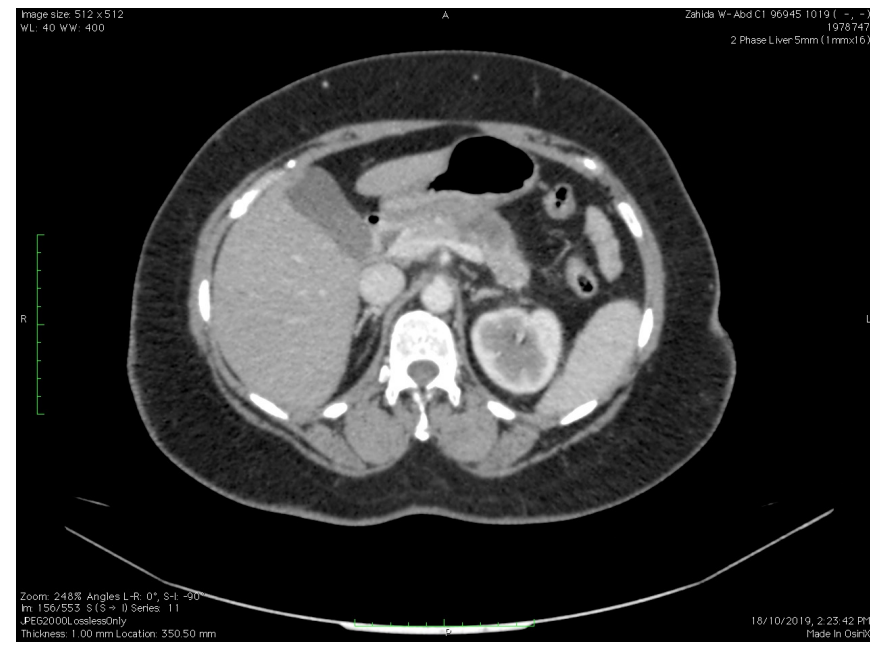

A

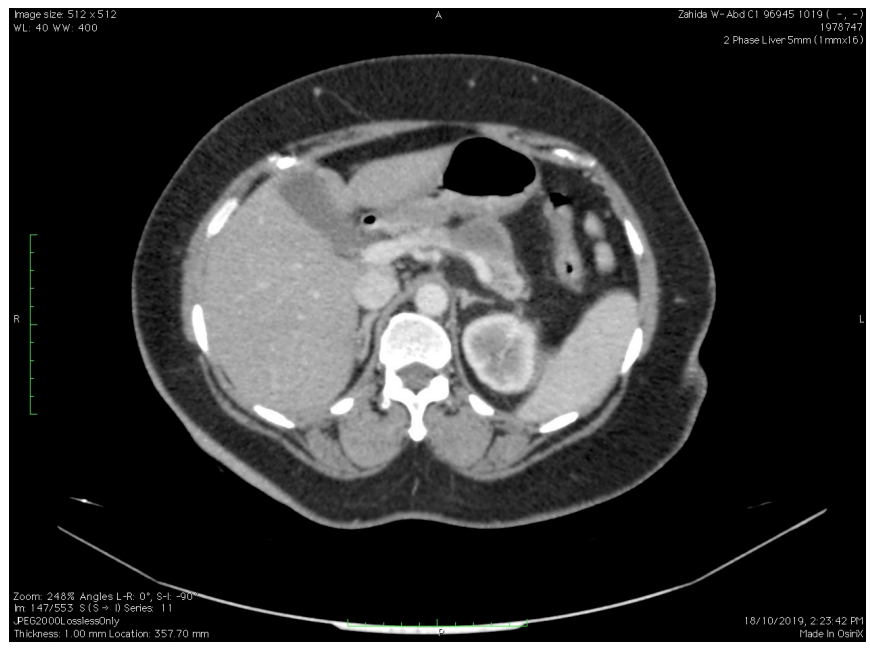

B

Fig. (1): MDCT images showing resectable pancreatic tumor in region of pancreatic body without any vascular invasion or metastatic diseases.

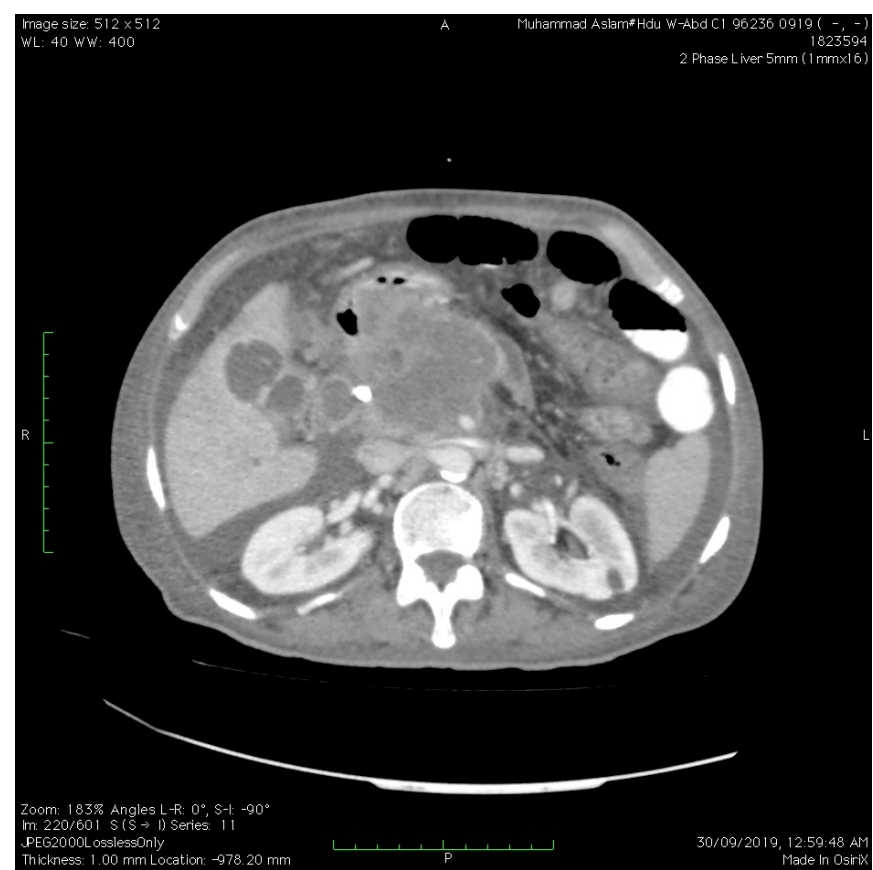

A

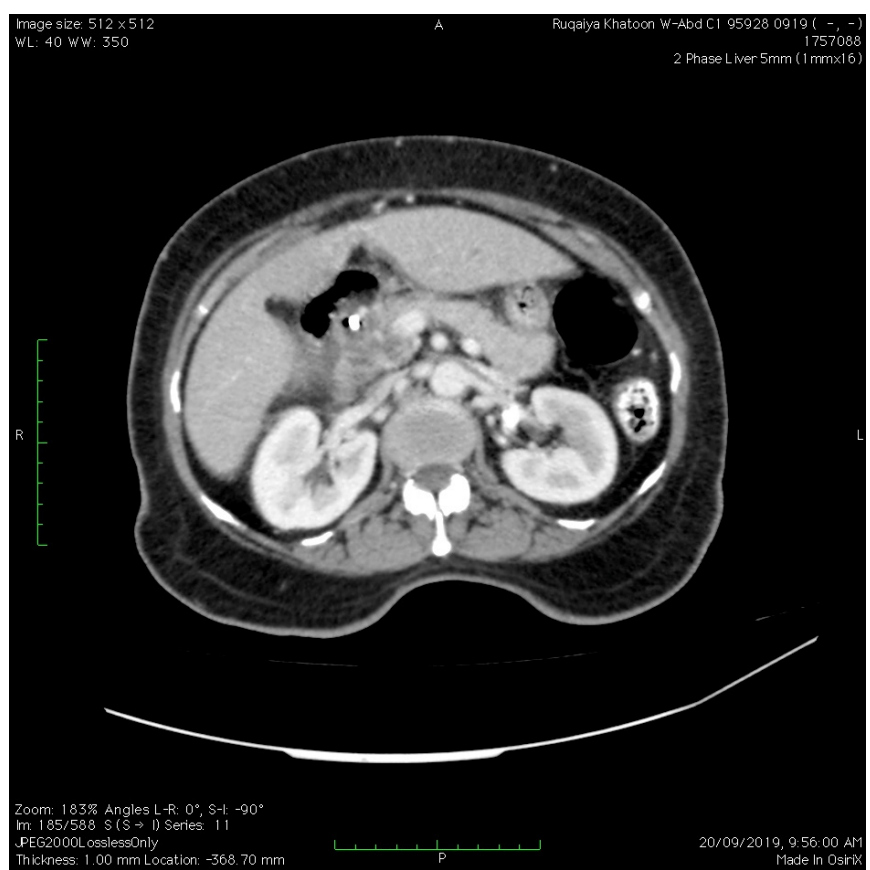

B

Fig. (2): MDCT images showing unresectable pancreatic tumor in the region of pancreatic head and body with vascular invasion.
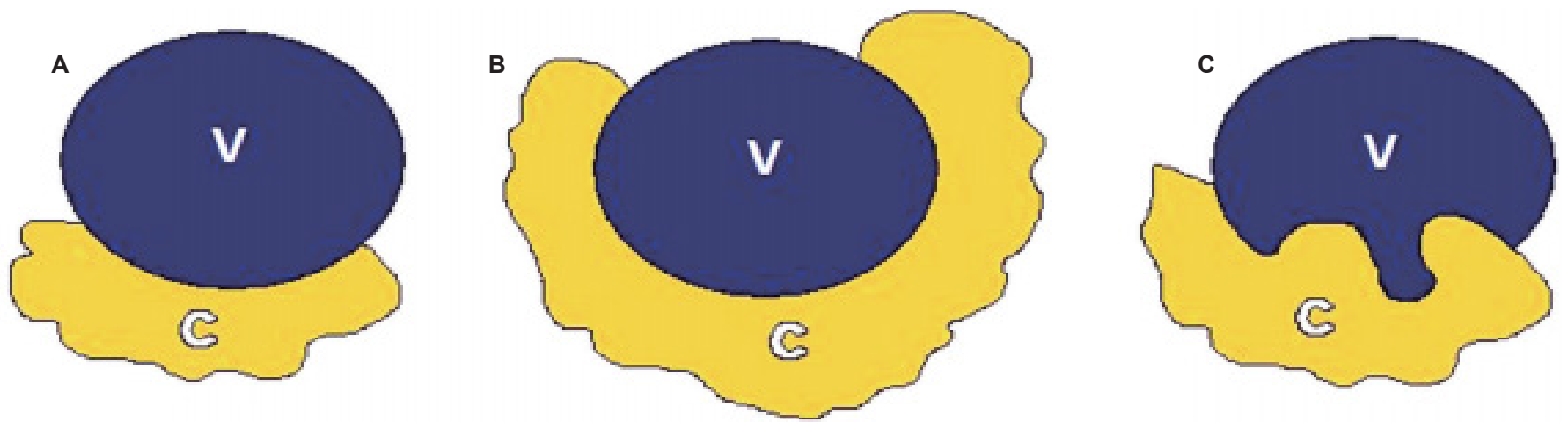

Fig. (3): Cartoon depiction of vascular involvement. (A) Abutment of $C$ with the $V$; (B) encasement; and (C) involvement/invasion with teardrop deformity. C, cancer, $\mathrm{V}$, vessel

Pietryga, J. and Morgan, D., 2015. Imaging Preoperatively For Pancreatic Adenocarcinoma. 


\section{DISCUSSION}

Pancreatic cancer is among the most deadliest malignancies with an increase incidence in developing countries [39]. Early diagnosis of pancreatic carcinoma is very important for therapeutic decisions and surgical planning. Surgical treatment is the only chance of cure when the disease is diagnosed in early phase [1]. MDCT is the modality of choice for the detection, diagnosis and detailed characterization of pancreatic tumors including metastatic disease. Pancreatic tumor is considered unresectable when there is vascular involvement (Figs. 2\&3) or there is presence of metastatic disease and this information is most important for the surgeon to plan patient management. In this study we used the definition of resectability and unresectability define by Evans et al. which is one of the most common definition used in the litertature.

In our study pancreatic carcinomas were more common in males $(57.1 \%)$ than in females $(42.9 \%)$. This was similar in study of Jamel A et al. who stated that age adjusted incident rate of pancreatic neoplasm is greater in men than in women [40].

Our findings are in contrast to Singal et al. who stated that pancretic neoplasm were more common in females $52 \%$ [41]. The mean age in our study is 62.5 years which is similar to study of Singal et al. (53years) [41] and also reported by Mark et al. (64.7years) [42].

In our study $44.4 \%$ of pancreatic tumors were found in pancreatic head while $20.6 \%$ tumors were found in pancreatic body and tail region respectively. Frency PC et al. [43] in his study reported $62 \%$ tumors in head, $26 \%$ in body and $12 \%$ in pancreatic tail regions.

In our study $14.3 \%$ of tumors were seen simultaneously involving body and tail regions.

In our study, pancreatic duct dilatation was seen in $66.7 \%$. These results were consistent with studies of Singal et al. [41] and Frency PC et al. [43].

The liver metastasis was $38.5 \%$ in our study. Murfitt $\mathrm{J}$ et al. [38] also stated that liver metastasis also occurs from $17 \%$ to $55 \%$ of patients. In our study out of 63 patients 14 patients (22.2\%) were diagnosed with resectable tumors at the time of MDCT. These findings lie in contrast to Singal et al. [41] who stated $60 \%$ of pancreatic lesions were resectable. This is likely because of advance disease at the time of presentation in our population. In our study the tumor size, peripancreatic nodes, contrast enhancement, vessel involvement, ascites, pleural effusion, hepatic metastasis, periphral organ involvement showed significant $p$-value in resectable and non resectable groups [44].

\section{CONCLUSION}

Accurate staging of pancreatic carcinoma is essential. MDCT is an excellent and most commonly used modality for diagnosis and staging of pancreatic carcinoma particularly with a high sensitivity for detection of vascular invasion and metastatic disease. Structured MDCT reporting should be adopted for pancreatic carcinomas as it has been shown to improve surgical planning and surgeons' confidence.

\section{LIMITATION}

Our study have a no. of limitations, some of which are due to retrospective study design, small sample size, lack of clinical and laboratory variables. Most of the patients presented with advanced disease which was sugically non resectable.We also lack in clinical outcomes of these patients with regards to morbidity, mortality and survival.

\section{CONFLICT OF INTEREST}

There are no potential conflicts of interest or any financial or personal relationships with other people or organization that could inappropriately bias conduct and finding of this study.

\section{ACKNOWLEDGEMENTS}

The authors would like to thank Ms. Noureen Durrrani, Biostatician at the Department of Publication, Liaquat National Hospital for her contribution in the statistical analysis of this study and Ms. Shazma Shamin, final year medical studnet from Ziauddin Medical University, for updating the data.

\section{REFERENCES}

1. Ganan M, Ángel Ríos LF, Octavio de Toledo LS, Martínez Mombila ME, Ros Mendoza LH. Staging pancreatic carcinoma by computed tomography. Radiología 2018; 60; 10-23.

2. Navarro S, Vaquero E, Maurel J, et al. Recomendaciones para el diagnostic, estadificación y tratamiento del cáncer de páncreas (parte I). Med Clin (Barc) 2010; 134: 692-702.

3. Siegel R, Naishadham D, Jemal A. Cancer statistics. CA Cancer J Clin 2012; 62: 10-29.

4. Al-Hawary M, Francis IR, Chari ST, et al. Pancreatic ductal adenocarcinoma radiology reporting template: consensus statement of the Society of Abdominal Radiology and the American Pancreatic Association. Radiology 2014; 270: 248-60.

5. Zaheer A, Wadhwa V, Oh J, Fishman EK. Pearls and pitfalls of imaging metastatic disease from pancreatic adenocarcinoma: a systematic review. Clin Imaging 2015; 39: 750-8.

6. Cassinotto C, Cortadea J, Belleannée G, et al. An evaluation of the accuracy of CT when determining resectability of pancreatic head adenocarcinoma after neoadjuvant treatment. Eur J Radiol 2013; 82: $589-93$

7. Hashemzadeh S, Mehrafsa B, Kakaei F, et al. Diagnostic accuracy of a 64-Slice Multi-Detector CT Scan in the preoperative evaluation of periampullary neoplasms. J Clin Med 2018; 7(5): 91.

8. Park H, Park S, Han S, Kim S. Surgery for elderly patients with resectable pancreatic cancer, a comparison with non-surgical treatments: a retrospective study outcomes of resectable pancreatic cancer. BMC Cancer 2019; 19(1): 1090.

9. Sapalidis K, Kosmidis C, Funtanidou V, et al. Update on current pancreatic treatments: from molecular pathways to treatment. $\mathrm{J}$ Cancer 2019; 10(21): 5162-72.

10. Ducreux M, Seufferlein T, Van Laethem J, et al. Systemic treatment of pancreatic cancer revisited. Semin Oncol 2019; 46(1): 28-38. 
11. Advances in Pancreatic Cancer. Spanish Society of Medical Oncology. Available from: https://seom.org/los-avances-encancer-de-pancreas (Accessed on: June 20, 2016).

12. Shen Y, Bai X, Li G, Liang T. Review of radiological classifications of pancreatic cancer with peripancreatic vessel invasion: are new grading criteria required? Cancer Imaging 2017; 17: 14.

13. Raman SP, Reddy S, Weiss MJ, et al. Impact of the time interval between MDCT imaging and surgery on the accuracy of identifying metastatic disease in patients with pancreatic cancer. AJR Am J Roentegnol 2015; 204: 37-42.

14. Mohammad A, Sara A. Systematic review of pancreatic cancer epidemiology in Asia-Pacific Region: major patterns in GLOBACON 2012. Gastroenterol Hepatol Bed Bench 2017; 10(4): 245-57.

15. Pourhoseingholi MA, Vahedi M, Baghestani AR. Burden of gastrointestinal cancer in Asia; an overview. Gastroenterol Hepatol Bed Bench 2015; 8: 19-27.

16. Parr CL, Batty GD, Lam TH, et al. Body-mass index and cancer mortality in the Asia-Pacific Cohort Studies Collaboration: pooled analyses of 424,519 participants. Lancet Oncol 2010; 11: 741-52.

17. Midha S, Chawla S, Garg PK. Modifiable and non-modifiable risk factors for pancreatic cancer: a review. Cancer Lett 2016; 381: 269-77.

18. Milena I, Irena I. Epidemiology of pancreatic cancer. World $\mathrm{J}$ Gastroenterol 2016; 22(44): 9694-705.

19. Takeshita K, Kutomi K, Haruyama T, et al. Imaging of early pancreatic cancer on multidetector row helical computed tomography. Br J Radiol 2010; 83(994): 823-30.

20. Ansari D, Tingstedt B, Andersson B, et al. Pancreatic cancer: yesterday, today and tomorrow. Future Oncol 2016; 12(16): 192946.

21. Ferlay J, Soerjomataram I, Ervik M, et al. GLOBOCAN 2012 v1.0, cancer incidence and mortality worldwide: IARC Cancer Base No. 11. Lyon, France: International Agency for Research on Cancer 2013.

22. Hidalgo M, Cascinu S, Kleeff J, et al. Addressing the challenges of pancreatic cancer: future directions for improving outcomes. Pancreatology 2013; 15: 8-18.

23. Vincent A, Herman J, Schulick R, Hruban RH, Goggins $M$. Pancreatic cancer. Lancet 2011; 378: 607-20.

24. Xiao AY, Tan ML, Wu LM, et al. Global incidence and mortality of pancreatic diseases: a systematic review, meta-analysis, and meta-regression of population-based cohort studies. Lancet Gastroenterol Hepatol 2016; 1: 45-55.

25. Dawoud MA, Youssef MA, Elbarbary AA. Role of multi-detector computed tomography in the evaluation of pancreatic tumors. Egypt J Radiol Nucl Med 2014; 45: 309-16.

26. Nino- Murcia M, Tamm EP, Charnsanagjevej C, Jeffrey Jr. RB. Multidetector row helical CT and advanced postprocessing techniques for the evaluation of pancreatic neoplasms. Abdom Imaging 2003; 28: 366-77.
27. Raj MP, Multidetector CT of the pancreas. Radial Clin N Am 200; 43: 999-1020.

28. Jason A, Diseree EM. Imaging preoperatively for pancreatic carcinoma. J Gastrointest Oncl 2015; 6(4): 343-57.

29. Tamm EP, Balachandran A, Bhosale PR, et al. Imaging of pancreatic adenocarcinoma: update on staging/resectability. Radiol clin North Am 2012; 50: 407-28.

30. Tempero MA, Arnoletti JP, Behrman S, et al. Pancreatic adenocarcinoma. J Natl Compr Canc Netw 2010; 8: 972-1017.

31. Wong JC, Lu DS. Staging of pancreatic adenocarcinoma by imaging studies. Clin Gastrointentrol Hepatol 2008; 6: 1301-8.

32. Legmann $P$, Vignaux $O$, Dousset $B$, et al. Pancreatic tumors comparison of dual phase helical CT and endoscope sonography. AJR Am J Roentgenol 1998; 170: 1315-22.

33. Nino M, Tamm EP, Carnsangavej C, Jeffery RS. Multislice CT and advanced post processing techniques for the evaluation of pancreatic neoplasms. Abdom Imaging 2005; 28: 366-77.

34. Sistrom CL, Honeyman- Buck J. Free text versus structured format: information transfer efficiency of radiology reports. AJR Am J Roentgenol 2005; 185: 804-12.

35. Naik SS, Hanbidge A, Wilson SR. Radiology reports examining radiologists and clinician preferences regarding style and content. AJR Am J Roentegnol 2001; 176: 591-8.

36. Schwartz LH, Paniceck DM, Berk AR, et al. Improving communication if diagnostic radiology finding through structured reporting. Radiology 2011; 260: 174-81.

37. Brook OR, Brook A, Vollmer CM, et al. Structured reporting of multiphasic CT for pancreatic cancer: potential effect on staging and surgical planning. Radiology 2015; 274: 464-72.

38. Murfitt J. The pancreas. In: Sutton D, Ed. Text book of radiology and medical imaging. London: Churchill Livingstone 2004: pp. 1079-98

39. Parvez T, Parvez B, Abdullah BN, et al. Advanced pancreatic cancer: past, present future of treatment. Pak armed forces med $\mathrm{J}$ 2005; 55(2): 146-55.

40. Jemal A, Siegal R, Xu J, Ward E. Cancer statistics, 2010. CA Cancer J Clin 2010; 60: 27-300.

41. Singhal S, Prabhu NK, Sethi $P$, et al. Role of multi detector computed tomography (MDCT) in preoperative staging of pancreatic carcinoma. J Clin Diagn Res 2017; 11(5):TC01-TC05.

42. Manak E, Merkel S, Klein $P$, et al. Resectibility of pancreatic adenocarcinomas assessment using multi detector row computed tomography with multi-planar reformations. Abdom Imaging 2009; 34(1): 75-80.

43. Freeny PC, Marks WM, Ryan JA, et al. Pancreatic ductal adenocarcinoma diagnosis and staging with dynamic CT. Radiology 1988; 166: 123-33.

44. Evans DB, Multidisciplinary Pancreatic Cancer Study Group. Resectable pancreatic cancer: the role for neoadjuvant/ preoperative therapy. HPB (Oxford) 2006; 8: 365-8. 